\title{
Speciation and Geochemical Behaviour of Heavy Metals in Industrial Area Soil of Mysore City, India
}

\author{
Doddaiah Shivakumar $^{1}$, Shivanna Srikantaswamy ${ }^{1 *}$, Swamy Sreenivasa ${ }^{2}$, Budiguppe Mahadevaiah Kiran ${ }^{1}$ \\ ${ }^{1}$ Department of Studies in Environmental Science, University of Mysore, Mysore, India; ${ }^{2}$ Department of Chemistry, Tumkur Univer- \\ sity, Tumkur, Karmataka. \\ Email: ${ }^{*}$ srikantas@hotmail.com
}

Received July $29^{\text {th }}, 2012$; revised August $29^{\text {th }}, 2012$; accepted September $27^{\text {th }}, 2012$

\begin{abstract}
Soil is a major reservoir for contaminants as it possesses an ability to bind various chemicals. These chemicals can exist in various forms in soil and different forces keep them bound to soil particles. It is essential to study these interactions because the toxicity of chemicals may strongly depend on the form in which they exist in the environment. Another thing is that soil variability and some environmental properties may change in soil and cause leaching of trace toxic elements like heavy metals tightly bound to soil particles. Metals associated with urban soil are of environmental concern because of their direct and indirect effects on human health. The main purposes of this study undertaken in the Mysore city industrial zone were to identify heavy metals with dangerous environmental load and to find out of their environmental impact ( $\mathrm{Fe}, \mathrm{Cr}, \mathrm{Cu}, \mathrm{Zn}$, and $\mathrm{Ni}$ ). The purpose of this work was to provide information on heavy metals concentration in industrial zone soil of Mysore city, India. Soil samples were analyzed for $\mathrm{pH}$, organic matter, and electrical conductivity. Total and available heavy metal concentrations were determined by AAS. In the present study, heavy metal speciation in soil sample carried out were shows that all metals were mainly associated with the oxidizable and residual fraction, which allows us to predict their mobility in the soil sample.
\end{abstract}

Keywords: Soil; Speciation of Heavy Metals; Sequential Extraction

\section{Introduction}

Soil is a dynamic system because of the presence of microorganisms and their biochemical activities are liberating a lot of enzymes in soil, which become stabilized in soil by binding to soil components. It exhibits continuous interplay between the living and non-living components. Soil pollution and contamination is a serious problem especially in country as densely populated as India. Due to rapid industrialization, the soil in the industrial areas are polluted by various toxic substances such as heavy metals, pesticides, dioxins, polyvinyl compounds and etc. The discharge of effluents from industries leads to changes in properties of soil. The disposal of biosolids on soil as a fertilizer for agriculture or as a regenerative for soil is the most attractive application since the biosolids act as a source of nutrients for crop production owing to their high content of organic matter [1,2]. However, this practice has the potential to create environmental pollution problems, because biosolids may contain toxic heavy metals $[3,4]$.

During the production of organic chemicals in indus-

${ }^{*}$ Corresponding author. tries, wastes generated are usually enter into the sewage system and thus cause pollution in soil which results in water-borne diseases. However, greater soil contamination may be present in more industrialized regions and in large city agglomerations. The city environment forms a mosaic of soil with different levels of mechanical surface transformations which changes the characteristics of soil and analysis of soil contamination very difficult. The majority of studies on the contamination of soil with heavy metals give importance to the determination of their content in a few soil samples without considering the specificity of their random and systematic variations.

Heavy metals are natural constituents of the Earth's crust. Human activities have drastically altered the balance and biochemical and geochemical cycles of some heavy metals. Therefore, the concentration of heavy metals in soil has been an issue of great interest in the past few years not only to ecologists, biologists and farmers but also environmentalists. An assessment of the environmental risk due to soil pollution is of particular importance for agricultural and non-agricultural areas, because heavy metals, which are potentially harmful to human health which is persist in soil for a very long time. In addition they may enter the food chain in significantly 
elevated amounts [5].

Diverse amounts of heavy metals may be found everywhere in soil, water, sediments, plants [6,7] and even the Arctic [8]. The emission sources of these xenobiotics have been studied for several years in order to reduce pollution. Chemicals like heavy metals once introduced to the environment by one particular method may spread to various environmental components, which may be caused by the nature of interactions occurring in this natural system. Heavy metals may chemically or physically interact with the natural compounds, which change their forms of existence in the environment. In general they may react with particular species, change oxidation states and precipitate [9].

It is well known that micronutrients such as Iron $(\mathrm{Fe})$, Manganese (Mn), Copper $(\mathrm{Cu})$ and $\mathrm{Zinc}(\mathrm{Zn})$ are essential metals for plants growth and yield. However, plants may accumulate heavy metals existing in soil, such as Cadmium (Cd), Nickel (Ni), Chromium (Cr) and Lead $(\mathrm{Pb})$ which are not essential for plant growth, but may cause serious problems to the environment. The concentration of heavy metals in soil solution plays a critical role in controlling the availability of ions to plants. Therefore the bioavailability of heavy metal ions varies widely because many factors influence their concentration in soil solution. The most important factors affecting metal availability are soil, clay content and organic matter content.

Heavy metals may be bound or sorbed by particular natural substances, which may increase or decrease mobility. Studying the dissipation of heavy metals is called speciation. In general two forms of speciation are distinguished by environmental scientists like chemical speciation and physical speciation. However chemical speciation may be distinguished further, it is said about group speciation, distribution speciation, individual speciation and many more [10].

Pollution problems may arise if toxic heavy metals are mobilized into the soil and are either taken up by plants or transported in drainage waters to associated water supplies. The metals may then enter the human food chain through the consumption of such plants or through intake of contaminated waters. Determination of total metal may provide information concerning possible pollution levels but generally there are insufficient details for estimating their biological effects, because it is the chemical form of the metal in the soil that determine its mobilization capacity and behaviour in the environment. An experimental approach commonly used for studying the mobility, transport and bioavailability of metals in soil is in the use of selective sequential extraction procedure. In operational defined speciation, the physical or chemical fractionation process applied to the sample defines the fraction obtained.
In sequential multiple extraction techniques different chemical extractants of various types are sequentially applied to the sample of sediment, soil or biosolid, each follow-up treatment being more drastic in chemical action or different in nature from the previous one. Applications of these methods have been used for street dust and roadside soil by Harrison et al. (1981) [11], biosolids by Pérez-Cid et al. (1996) [12] , Rudd et al. (1986) [13], and Ure and Davidson (1995) [14], incinerated sludge ash by Fraser and Lum (1983) [15] and Vela et al. (1993) [16], sediments by Gonzalez et al. (1995) [17], Rauret et al. (1989) [18] and Quevauviller et al. (1993) [19] and soil by Cañadas et al. (1986) [20], Lindsay (1979) [21] and Li et al. (1995) [22]. Many of these schemes are based on the five-stage schemes developed by Tessier et al. (1979) [23], method or its modifications by Rauret et al. (1989) [24]. These steps are designed to differentiate between the exchangeable, carbonate, reducible (hydrous $\mathrm{Fe} / \mathrm{Mn}$ oxides), oxidizable (sulfides and organic phases) and residual (mineral) fractions.

The presence of Zinc, Copper, Nickel and Chromium are the principal elements in soil which restricts uses of land for agriculture. Their potential accumulation in human tissues and bio magnification through the food chain cause both human health and environmental concerns. These considerations are usually based on total heavymetal content in soil. However, it is now widely accepted the determination of total elements does not give an accurate estimation of the potential environmental impact. This is due to that both bioavailability and toxicity are critically dependent on the chemical form of heavy metals.

The main aim of this present study is to investigate the potential pollution of heavy metals are present in the soil of industrial area followed by the study of speciation of chromium, copper, iron and nickel by the sequential extraction procedure proposed by Tessier $e t$ al.

\section{Materials and Methods}

The soil for the present study have been collected from industrial area of Mysore city, Karnataka, India (Figure 1). The study area Mysore is having more than 9 lakh populations and was capital of former princely state of Karnataka. It lies between $12^{\circ} 9^{\prime}$ and $11^{\circ} 6^{\prime}$ latitude and $77^{\circ} 7^{\prime}$ longitude and general elevation is little more than $1800 \mathrm{ft}$ above sea level. The climate of the city is moderated throughout the year with temperature during summer ranging from $30^{\circ} \mathrm{C}$ to $34^{\circ} \mathrm{C}$. The rainy season is from May to October. The winter season is from November to February. For domestic and industrial purposes, the main source of water is mainly from the Cauvery River and ground water.

Mysore is one of the growing cities of Karnataka and 


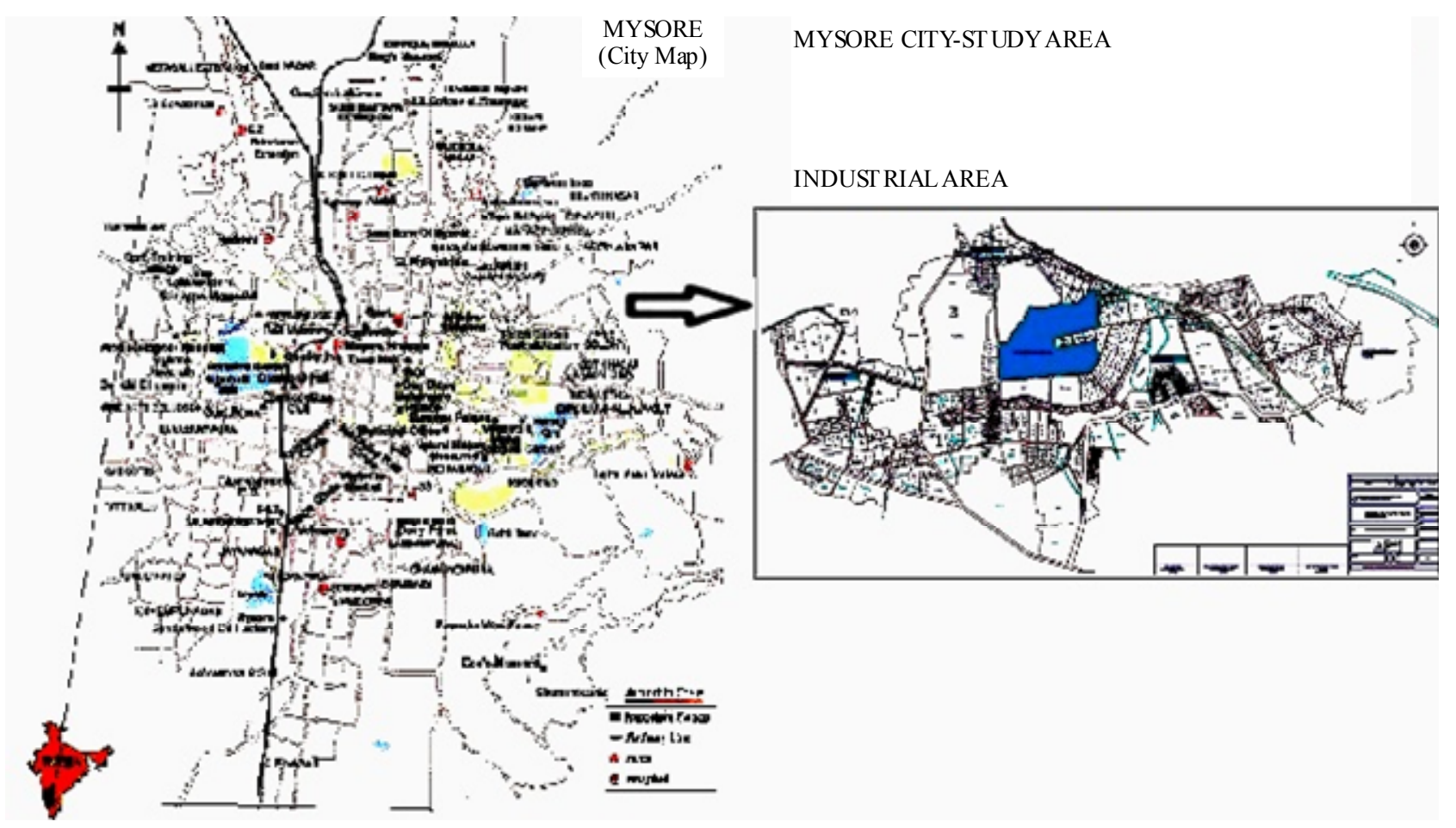

Figure 1. Industrial area of Mysore city (Sample locations).

it is so largely due to presence of industrial resources and a well developed communication network. Mysore has a rich and vibrant history and heritage and hence attracts a huge number of tourists. Also Mysore is now active centre for production and industrialisation. The city has been growing as a country magnet to Bangalore. With a large presume of software companies and the population is growing at a faster rate due to the influx of many industrial and commercial activities.

In recent year's industrialization has become main cause of city's growth. There is diversity in industrial landscape of Mysore with haphazard distribution. The industrial area's are distributed all over the city and its surroundings with lack of order and regulation in industrial location. A large number of small and medium scale industries exists in and around the Mysore city. Most of all medium scale industries we found engineering chemical, pharmaceutical food brewery, textile, steel and metal smelting.

In Hebbal industrial area small scale industries and medium scale industries are more in number compared to large scale industries like electrical appliances industries, textile industry metal product industries.

Hootagalli industrial area is smaller in its size as compared to metagalli and Hebbal industrial areas. Here the industries like textile, heavy earth movers manufacturing industry and very few small scale industries are situated. In the present study sample locations were widely distributed in the study area and nine representative samples were collected.

\section{Sampling and Pre-Treatment of the Sample}

The soil samples were collected at different points of the industrial zone of Mysore city, India. The soil samples are collected quarterly during 2011. The samples collected for the present study is during the second quarter of 2011. Soil samples were dried with the help of oven in the laboratory and then ground in an agate mortar and pestle to pass through a $0.5 \mathrm{~mm}$ stainless steel sieve. Then they were stored in polythene covers at room temperature. The soil samples were analyzed for basic physicochemical properties using standard analytical methods.

\section{Multi-Step Sequential Extraction}

The sequential extraction procedure used in this study is Tessier et al. 1979 method. According to Tessier et al. heavy metals are associated with the fractions as described as follows:

1) The exchangeable fraction, which is likely to be affected by changes in water ionic composition as well as sorption-desorption processes;

2) The carbonate fraction, that is susceptible to changes in $\mathrm{pH}$;

3) The reducible fraction, that consists of iron and manganese oxides which are unstable under anoxic conditions; 
4) The organic fraction, that can be degraded leading to a release of soluble metals under oxidizing conditions;

5)The residual fraction that contains mainly primary and secondary minerals, which may hold metals within their structure. These metals are not expected to be released in solution over a reasonable time span under the conditions normally encountered in nature [25]. The extraction was carried out progressively on an initial mass of $1.00 \mathrm{~g}$ of sample of soil samples. The samples for sequential extraction were dried in an oven at $60^{\circ} \mathrm{C}$ for $24 \mathrm{~h}$ in order to avoid, as far as possible, the transformation of some chemical forms (exchangeable and carbonate). This procedure is having five steps fractionization. The extractants and operationally defined chemical fractions were as follows:

Fraction 1 (F1): Exchangeable metal fraction.

The sample was extracted with $8 \mathrm{ml}$ of $1 \mathrm{M} \mathrm{MgCl}_{2}$ for $1 \mathrm{~h}$ with continuous agitation, at room temperature.

Fraction 2 (F2): Carbonate bound metal fractions.

The residue from $\mathrm{F} 1$ was leached for $5 \mathrm{~h}$ with $8 \mathrm{ml}$ of $1 \mathrm{M}$ sodium acetate adjusted to $\mathrm{pH} 5.0$ with acetic acid, at room temperature and with agitation.

Fraction 3 (F3): Elements associated with Fe-Mn oxide metal fraction.

The residue from F2 was extracted with $20 \mathrm{ml}$ of 0.04 M hydroxylamine hydrochloride in $25 \%$ acetic acid for 5 $\mathrm{h}$ in boiling water bath and with periodic agitation.

Fraction 4 (F4): Organic and sulfide metal fractions.

The residue from $\mathrm{F} 3$ was extracted with $3 \mathrm{ml}$ of 0.02
$\mathrm{M} \mathrm{HNO}_{3}$ and $8 \mathrm{ml}$ of $30 \% \mathrm{H}_{2} \mathrm{O}_{2}$ adjusted to $\mathrm{pH} 2.0$ with $\mathrm{HNO}_{3}$ for $5 \mathrm{~h}$ at $85^{\circ} \mathrm{C}$ with occasional agitation and then at room temperature with $5 \mathrm{ml}$ of $3.2 \mathrm{M}$ ammonium acetate in $20 \% \mathrm{HNO}_{3}$.

Fraction 5 (F5): Residual metal fraction.

This fraction was calculated as the difference between the total metals and the sum of extracted metals. The selective extractions were conducted in $50 \mathrm{~mL}$ capacity centrifuge tubes. After each extraction step, the sample was subjected to $30 \mathrm{~min}$ of centrifugation at $4000 \mathrm{rpm}$, the supernatant was separated from the residue with a pipette and transferred into a $25-\mathrm{mL}$ calibrated flask. The residue was centrifugation and later washed thoroughly, the obtained second supernatant was added to the flask, which was diluted to the desired volume. The extracts obtained were acidified using aquaregia and stored in stopper polyethylene vessels until their analysis by using inductively coupled plasma atomic emission spectroscopy techniques (ICP-AES). The total content of metals was determined after digesting $0.4 \mathrm{~g}$ of sample with aquaregia. The concentration of particular heavy metals was expressed per $1 \mathrm{~kg}$ of air dry sample. The content of heavy metals in the obtained solution was determined by using ICP-AES.

\section{Results and Discussion}

Speciation of metals was carried out according to Tessier method as described earlier. Table 1 shows the results of total content of particular heavy metals in soil of Industrial

Table 1. Total content of metals in the industrial area soil of Mysore and its distrubution among particular fractions.

\begin{tabular}{|c|c|c|c|c|c|c|}
\hline & \multicolumn{6}{|c|}{ Location P1 } \\
\hline & Fractions I & Fractions II & Fractions III & Fractions IV & Fractions V & Total \\
\hline $\mathrm{Fe}$ & 2.0 & 17 & 380 & 600 & 2700 & 3699 \\
\hline $\mathrm{Cu}$ & ND & ND & ND & 4.8 & 13.5 & 18.3 \\
\hline $\mathrm{Cr}$ & ND & ND & 4.2 & 3.6 & 2.2 & 10.0 \\
\hline $\mathrm{Zn}$ & ND & 7.8 & 58 & 6.3 & 11 & 83.1 \\
\hline \multirow[t]{3}{*}{$\mathrm{Ni}$} & ND & ND & 2.4 & 7.5 & 2.1 & 12.0 \\
\hline & \multicolumn{6}{|c|}{ Location P2 } \\
\hline & Fractions I & Fractions II & Fractions III & Fractions IV & Fractions V & Total \\
\hline $\mathrm{Fe}$ & 2.0 & 12 & 262 & 971 & 2400 & 3647 \\
\hline $\mathrm{Cu}$ & ND & ND & ND & 1.8 & 13.0 & 14.8 \\
\hline $\mathrm{Cr}$ & ND & ND & 1.1 & 1.3 & 1.6 & 4.0 \\
\hline $\mathrm{Zn}$ & 1.7 & 8.9 & 46 & 11 & 04 & 71.6 \\
\hline \multirow[t]{3}{*}{$\mathrm{Ni}$} & ND & ND & 4.3 & 2.4 & 8.3 & 15.0 \\
\hline & \multicolumn{6}{|c|}{ Location P3 } \\
\hline & Fractions I & Fractions II & Fractions III & Fractions IV & Fractions V & Total \\
\hline $\mathrm{Fe}$ & 7.2 & 18 & 930 & 3100 & 1500 & 5555.2 \\
\hline $\mathrm{Cu}$ & ND & ND & ND & 1.2 & 16.6 & 17.8 \\
\hline
\end{tabular}




\section{Continued}

\begin{tabular}{|c|c|c|c|c|c|c|}
\hline $\mathrm{Cr}$ & ND & ND & 2.8 & 3.2 & 5.0 & 11.0 \\
\hline $\mathrm{Zn}$ & ND & 14 & 39 & 9.4 & 5.6 & 68.0 \\
\hline $\mathrm{Ni}$ & ND & 1.3 & 4.2 & 1.1 & 3.4 & 10.0 \\
\hline & \multicolumn{6}{|c|}{ Location P4 } \\
\hline & Fractions I & Fractions II & Fractions III & Fractions IV & Fractions V & Total \\
\hline $\mathrm{Fe}$ & 4.0 & 30 & 820 & 1700 & 4200 & 6754 \\
\hline $\mathrm{Cu}$ & ND & ND & ND & 4.7 & 13.6 & 18.3 \\
\hline $\mathrm{Cr}$ & ND & ND & ND & 4.3 & 7.6 & 11.9 \\
\hline $\mathrm{Zn}$ & 0.9 & 18 & 50 & 7.9 & 12.2 & 89.0 \\
\hline \multirow[t]{3}{*}{$\mathrm{Ni}$} & ND & ND & 7.1 & 1.2 & 3.7 & 12.0 \\
\hline & \multicolumn{6}{|c|}{ Location P5 } \\
\hline & Fractions I & Fractions II & Fractions III & Fractions IV & Fractions V & Total \\
\hline $\mathrm{Fe}$ & 3.7 & 8.4 & 940 & 2800 & 2500 & 6252.1 \\
\hline $\mathrm{Cu}$ & ND & ND & ND & 1.6 & 16.4 & 18.0 \\
\hline $\mathrm{Cr}$ & ND & 0.9 & 3.1 & 2.8 & 4.2 & 11.0 \\
\hline $\mathrm{Zn}$ & ND & 16 & 41 & 15 & 22 & 94.0 \\
\hline \multirow[t]{3}{*}{$\mathrm{Ni}$} & ND & ND & 7.5 & 3.9 & 3.6 & 14.0 \\
\hline & \multicolumn{6}{|c|}{ Location P6 } \\
\hline & Fractions I & Fractions II & Fractions III & Fractions IV & Fractions V & Total \\
\hline $\mathrm{Fe}$ & 2.4 & 10.6 & 267 & 1856 & 2150 & 4286 \\
\hline $\mathrm{Cu}$ & ND & ND & ND & 1.2 & 12.7 & 13.9 \\
\hline $\mathrm{Cr}$ & ND & ND & 1.1 & 3.9 & 4.0 & 9.0 \\
\hline $\mathrm{Zn}$ & 3.0 & 8.8 & 53.0 & 19 & 14.0 & 97.8 \\
\hline \multirow[t]{3}{*}{$\mathrm{Ni}$} & ND & ND & 3.6 & 5.8 & 6.4 & 15.8 \\
\hline & \multicolumn{6}{|c|}{ Location P7 } \\
\hline & Fractions I & Fractions II & Fractions III & Fractions IV & Fractions V & Total \\
\hline $\mathrm{Fe}$ & 2.8 & 12.2 & 317 & 1716 & 2261 & 4309 \\
\hline $\mathrm{Cu}$ & ND & ND & ND & 12.7 & 3.9 & 16.6 \\
\hline $\mathrm{Cr}$ & ND & ND & 1.3 & 3.6 & 5.1 & 10.0 \\
\hline $\mathrm{Zn}$ & ND & 11 & 56 & 30 & 2.0 & 99.0 \\
\hline \multirow[t]{3}{*}{$\mathrm{Ni}$} & ND & ND & 1.4 & 4.2 & 6.8 & 12.4 \\
\hline & \multicolumn{6}{|c|}{ Location P8 } \\
\hline & Fractions I & Fractions II & Fractions III & Fractions IV & Fractions V & Total \\
\hline $\mathrm{Fe}$ & 3.1 & 12 & 179 & 816 & 1359 & 2369.1 \\
\hline $\mathrm{Cu}$ & ND & ND & ND & 2.9 & 3.9 & 6.8 \\
\hline $\mathrm{Cr}$ & ND & ND & ND & 8.4 & 7.6 & 16.0 \\
\hline $\mathrm{Zn}$ & 1.7 & 8.9 & 33 & 41.3 & 2.1 & 87.0 \\
\hline \multirow[t]{3}{*}{$\mathrm{Ni}$} & ND & 1.3 & 4.2 & 1.7 & 2.8 & 10.0 \\
\hline & \multicolumn{6}{|c|}{ Location P9 } \\
\hline & Fractions I & Fractions II & Fractions III & Fractions IV & Fractions V & Total \\
\hline $\mathrm{Fe}$ & 3.6 & 71 & 347 & 866 & 2156 & 3379.7 \\
\hline $\mathrm{Cu}$ & ND & ND & ND & 3.2 & 7.1 & 10.3 \\
\hline $\mathrm{Cr}$ & ND & ND & 1.6 & 5.2 & 7.2 & 14.0 \\
\hline $\mathrm{Zn}$ & 10.2 & 15 & 53 & 31.4 & 2.0 & 111.6 \\
\hline $\mathrm{Ni}$ & ND & ND & 7.2 & 2.8 & 2.0 & 13.0 \\
\hline
\end{tabular}

(All Fractions Expressed in $\mathrm{mg} / \mathrm{kg}$ ). 
area located at Mysore and its distribution among particular fractions. The exchangeable fraction (F1) contains metal elements in the ionic form, which have a high mobility and can be drained by water. The fraction related to the carbonates (F2) is extractable and can be accumulated in the plants. The fraction related to the oxides of iron and manganese (F3) and that related to organic matter (F4) contain metals enclosed in the matrix. The fraction (F5) contains the inert metals.

The results show that iron occurred mainly in residual fraction which is varied between $27 \%$ and $72 \%$ in different samples and also $16.22 \%$ to $55.8 \%$ of iron is bound to organic matter. It is bound in much smaller amounts in the form of oxides fraction which ranged from $6.22 \%-16.74 \%$ in different samples. Also only minor amounts of iron were detected in the exchangeable and bound to carbonate fractions. Similar results were reported by Kwapulinski and Wiechula (1993) [26].

The analysis shows that zinc has been bound to hydrated oxides of iron and manganese fraction and varied in different samples in the range of $37.9 \%-69.79 \%$ and also was bound to organic matter fraction in range of $7.5 \%-47.4 \%$. The amount of zinc found in the residual fractions was varies from $1.79 \%-23.4 \%$. In exchangeable fraction the metal concentration was below the detection limit in some soil samples and for remaining samples it is ranged from $1.01 \%-9.13 \%$.

In the present study, nickel is mainly found in the fraction bound to organic that is varies from $10 \%-62.5 \%$, whereas $16.66 \%-55.3 \%$ in residual fraction. Bounded to oxide metal fraction for nickel is $11.2 \%-60 \%$ and $13 \%$ in carbonate bound fraction. The level of nickel found in exchangeable metal fraction is once again lower than the detection limit. Toxicity of nickel is not important because of its low concentration in the mobile and bioavailable fractions.

The analysis shows that copper in the different soil samples have been found in organic matter fraction ranged from $6.75 \%-76.5 \%$ and varied in the range of $23.4 \%$ $93.2 \%$ in residual form. The level of copper in the exchangeable, carbonate fraction and fractions bound to hydrated oxides of iron and manganese and was lower than the detection limit. Copper is bound much more tightly by organic matter than $\mathrm{Ni}$ and is much less likely to be displaced by the hydroxylamine hydrochloride reagent. Similar results are reported by McLaren and Clucas (2001) [27]. Copper in the soil is not present in the ionic forms which reduce its toxicity.

The speciation analysis shows that chromium, in the soil sample is mainly found in the residual fraction in the range from $22 \%-63.8 \%$ and little lesser in the range of $24.45 \%-52.5 \%$ bound to the organic matter. Whereas in smaller amounts ranges from $11.42 \%-42 \%$ in the fractions bound to hydrated iron and manganese oxides frac- tions. Thus, the bioavailability of chromium in the soil sample is considered insignificant. It is below detection limit in exchangeable and carbonate bound fraction.

In exchangeable fraction, except Iron and Zinc, the concentration of all metals in this fraction is lower than the detection limit. The amounts of metals released in the carbonate fraction represent a low proportion of the total metal concentration. Copper, Chromium and Zinc are below the detection range and Iron has low concentrations in this fraction. This fraction is susceptible to acid rain [28]. In the fractions bound to hydrated iron and manganese oxides, the amounts of Nickel, Iron and Zinc associated are relatively high. These amounts of metals would be released under reducing conditions. The metal levels in fraction associated with organic matter are relatively high and they represent a large fraction of the total metal concentrations. These amounts of metals are released in soil under strong oxidizing conditions and consequently this fraction constitutes an important source of potentially available trace metals. It can be observed that the greatest part of the metals studies, especially iron was associated with the residual fraction. This fraction, named "inert phase", corresponds to the part of the metals which cannot be mobilised.

\section{SEM and EDAX Analysis}

Soil collected were further analysed by using Scanning Electron Microscope (SEM, JSM-840A, JEOL, USA), equipped with an energy-dispersive X-ray spectroscopy (ED$\mathrm{AX}$ ) to study the texture and surface features of powders or solid pieces and EDAX is very useful for qualitative as well as quantitative analysis of relative concentration of elements detected. SEM image and distribution of elements (EDAX) of the soil collected from three representative industrial sites located at Mysore are shown in Figures $\mathbf{2}$ and $\mathbf{3}$ respectively.

The morphologies of selected samples are exhibited in Figure 2. Soil shows that, flakes with porous aggregation with abundant, tiny clusters of fine flakes, which are probably clay flakes.

Figure 3 shows that, semi quantitative analysis of samples by EDX. The variations in chemical compositions $=$ reflect the relative abundance of significant chemical species. Soil from Hebbal industrial area is exceptionally rich in Iron with $23.35 \%$ suggesting the participation of iron complexes. In all the soil $\mathrm{Si}, \mathrm{Al}$ and $\mathrm{Ca}$ are rich in composition which attributed that the presence of more clay minerals.

\section{Conclusion}

The results obtained in the present study of heavy metal speciation in soil sample indicated that all metals were mainly associated with the oxidizable and residual 

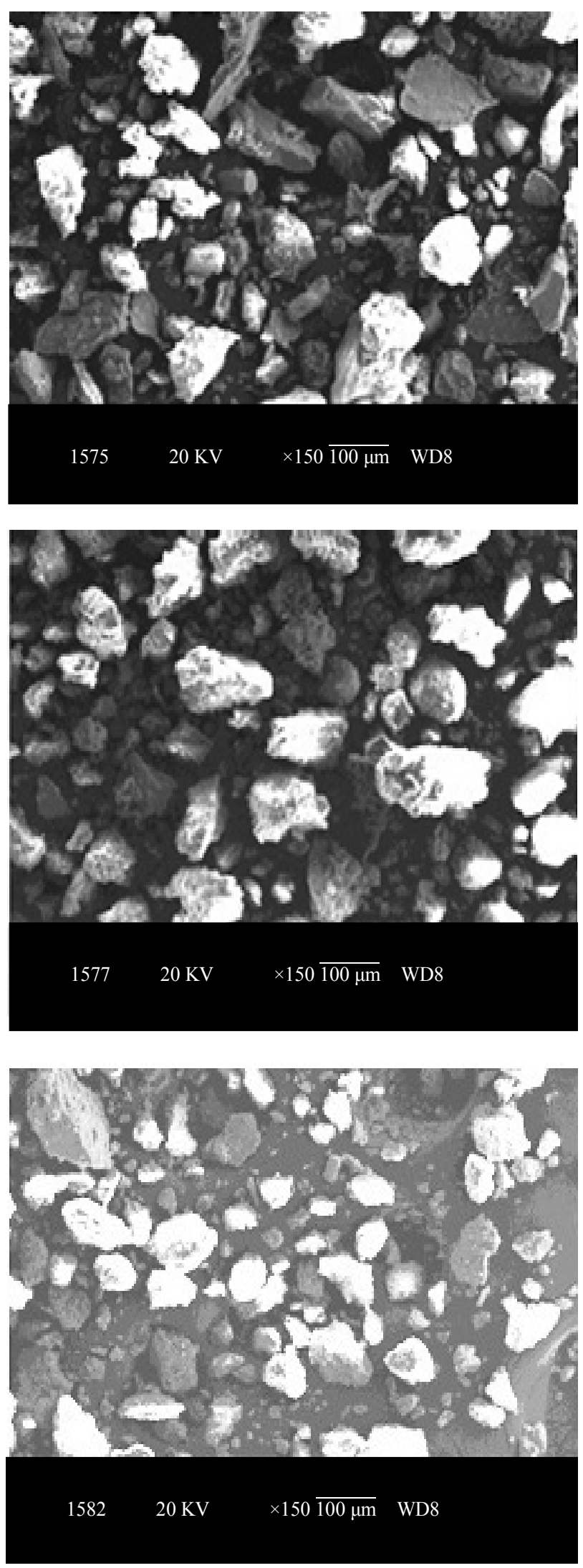

Figure 2. SEM images showing the morphology of soil collected from industrial area of Mysore.

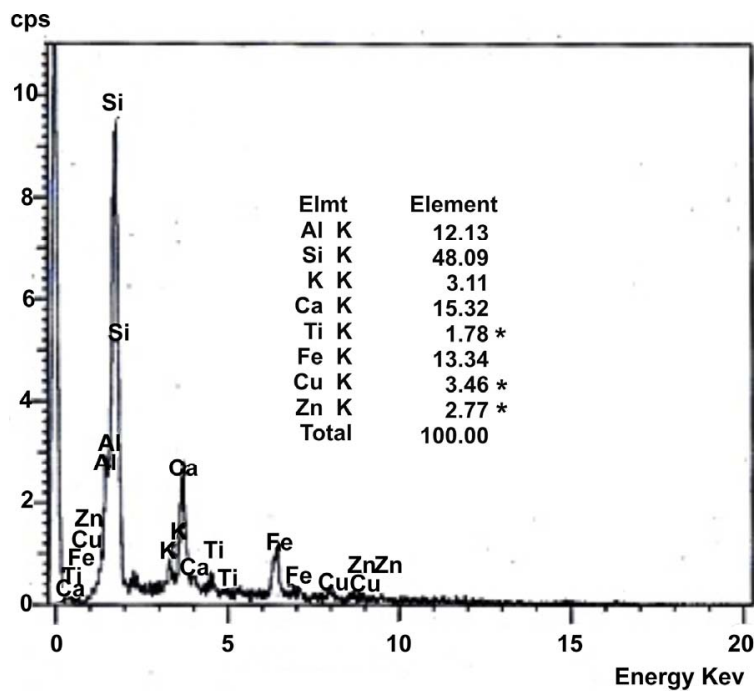

(a)

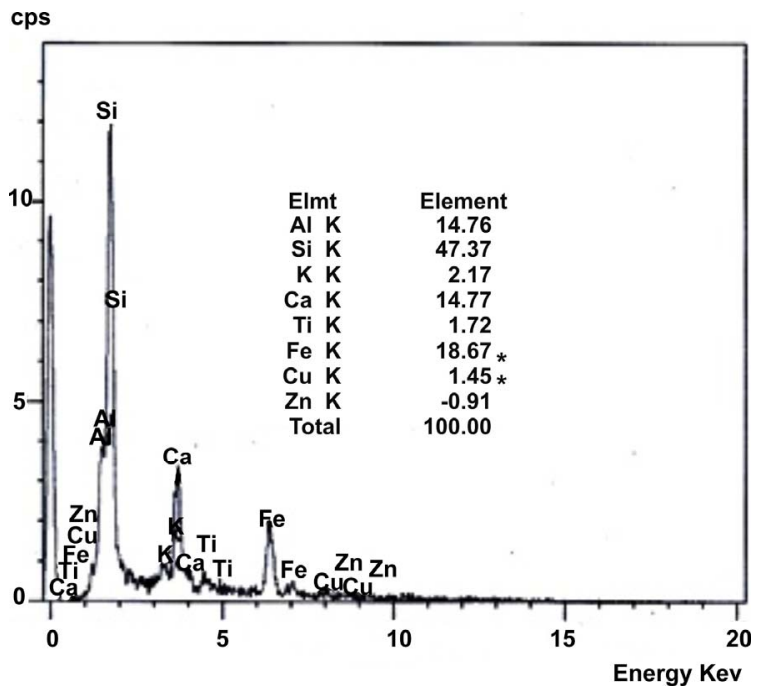

(b)

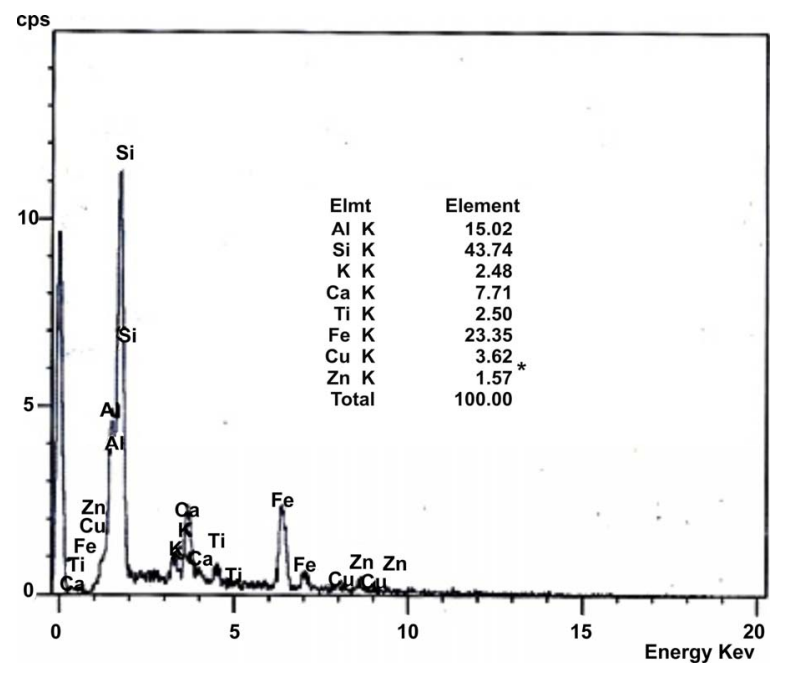

(c)

Figure 3. EDAX and qualitative analysis of soil collected from industrial area of Mysore. 
fraction, which allows us to predict their mobility in the soil sample. The residual fraction has the maximum percentage of heavy metals, whereas only a small fraction of heavy metals $(\mathrm{Fe}, \mathrm{Cu}, \mathrm{Cr}, \mathrm{Zn}$ and $\mathrm{Ni})$ is extracted in soluble fractions, exchangeable and carbonate fractions. It indicates that the bioavailability index is low. The present study of the mobility and availability of heavy metals by sequential extraction has been proved to be of great significance in providing valuable information, since the toxicity of heavy metal is related to its mobility and availability. Heavy metal presence was identified through speciation study at all the sampling location. Further it may have the chances of up taking the heavy metals by the surrounding vegetation, which could cause the serious problems of bio accumulation and bio magnification. This research work indicated that application of sequential extraction procedures for determination of speciation of heavy metals in soil of industrial area provides an assessment of the real mobility of these elements.

\section{Acknowledgements}

Authors are thankful to University Grants Commission, New Delhi, for awarding the major research project.

\section{REFERENCES}

[1] J. Casado-Vela, S. Sellés, C. Díaz-Crespo, J. NavarroPedrenõ, J. Mataix-Beneytob and I. Gómez, "Effect of Composted Sewage Sludge Application to Soil on Sweet Pepper Crop (Capsicum Annuum Var. Annuum) Grown Under Two Exploitation Regimes," Waste Management, Vol. 27, No. 11, 2007, pp. 1509-1518.

[2] C. García, T. Hernández and F. Costa, "The Influence of Composting on the Fertilizing Value of Anaerobic Sewage Sludge," Plant and Soil, Vol. 136, No. 2, 1991, pp. 269-272. doi:10.1007/BF02150059

[3] S. Bai, S. Srikantaswamy, V. Krishnanandan and O. P. Naik, "Speciation of Heavy Metals in Biosolids of Wastewater Treatment Plants at Mysore, Karnataka, India," Environmental Monitoring and Assessment, Vol. 184, No. 1, 2012, pp. 239-249. doi:10.1007/s10661-011-1964-3

[4] M. L. A. Silveira, L. R. F. Alleoni and L. R. G. Guilherme, "A Review on Biosolids and Heavy Metals in Soils," Scientia Agricola, Vol. 60, No. 4, 2003, pp. 793-806. doi:10.1590/S0103-90162003000400029

[5] N. S. Chary, C. T. Kamala and D. S. S. Raj, "Assessing Risk of Heavy Metals from Consuming Food Grown on Sewage Irrigated Soils and Food Chain Transfer," Ecotoxicology and Environmental Safety, Vol. 69, No. 3, 2008, pp. 513-524. doi:10.1016/j.ecoenv.2007.04.013

[6] P. Szefer, "Distribution of Trace Metals in the Pacific Oyster, Crassostrea gigas, and Crabs from the East Coast of Kyushu Island, Japan," Bulletin of Environmental Contamination and Toxicology, Vol. 58, No. 1, 1997, pp. 108114. doi:10.1007/s001289900307

[7] G. P. Glasby and Szefer, "Marine Pollution in Gdansk
Bay and the Vistula Lagoon, Poland: An Overview," Science of the Total Environment, Vol. 212, No. 1, 1998, pp. 49-57.

[8] J. M. Pacyna, "Global Perspectives on Lead, Mercury and Cadmium Cycling in the Environment," Wiley Eastern Ltd., New Delhi, 1994, pp. 315-328.

[9] A. Dube, T. Kowalkowski, R. Zbytniewski, P. Kosobucki, E. Cukrowska and B. Buszewski, "Chemical Speciation of Heavy Metals in Environmental Samples," Proceedings of the 15th International Symposium on PhysicoChemical Methods of the Mixtures Separation-Arsseparatoria' 2000, Borowno N. Bydgoszcz, Poland, 14-17 June 2000, p. 21.

[10] A. Kot and J. Namiesnik, "Trends in Analytical Chemistry," Vol. 19, 2000, p. 69.

[11] R. M. Ison, D. P. H. Laxen and S. J. Wilson, "Chemical Association of Lead, Cadmium, Copper and Zinc in Street Dust and Roadside Soil," Environmental Science \& Technology, Vol. 15, No. 11, 1981, pp. 1378-1383. doi:10.1021/es00093a013

[12] B. Pérez-Cid, I. Lavilla and C. Bendicho, "Analytical Assessment of Two Sequential Extraction Schemes for Metal Partitioning in Sewage Sludges," Analyst, Vol. 121, No. 10, 1996, pp. 1479-1484. doi:10.1039/an9962101479

[13] T. Rudd, J. A. Campbell and J. N. Lester, "Characterisation of Metal Forms in Sewage Sludges by Chemical Extraction," In: J. N. Lester, R. Perry and R. M. Sterritt, Eds., Chemicals in the Environment, Selper, London, 1986, pp. 756-771.

[14] A. M. Ure and C. M. Davidson, "Chemical Speciation in the Environment," Blackie, Glasgow, 1995.

[15] J. L. Fraser and K. M. Lum, "Availability of Elements of Environmental Importance in Incinerated Sludge Ash," Environmental Science \& Technology, Vol. 17, No. 1, 1983, pp. 52-54. doi:10.1021/es00107a013

[16] L. D. Vela, R. E. Jervis and S. S. Krishnan, "The Leachability of Elements in Solid Wastes," Journal of Radioanalytical and Nuclear Chemistry, Vol. 169, No. 1, 1993, pp. 39-45. doi:10.1007/BF02046781

[17] M. J. Gonzalez, L. Ramos and L. M. Hernández, "Organochlorine and Heavy Metal Residues in the Water/ Sediment System of the South East Regional Park in Madrid, Spain," International Journal of Environmental Analytical Chemistry, Vol. 57, No. 2, 1995, pp. 135-150. doi:10.1080/03067319408027419

[18] G. Rauret, R. Rubio, J. F. López-Sanchez and E. Casassas, "Specific Procedure for Metal Solid Speciation in Heavily Polluted River Sediments," International Journal of Environmental Analytical Chemistry Vol. 35, No. 2, 1989, pp. 89-100. doi:10.1080/03067318908028382

[19] Ph. Quevauviller, G. Rauret and B. Griepink, "Single and Sequential Extraction in Sediments and Soil," International Journal of Environmental Analytical Chemistry, Vol. 51, No. 1-4, 1993, pp. 231-235. doi:10.1080/03067319308027629

[20] R. C. Canadas, J. Rodriguez and V. Cala, "Distribution of $\mathrm{Pb}, \mathrm{Cd}, \mathrm{Cu}$ and $\mathrm{Cr}$ between Solid Phases in Some Soil Types," Journal of Soil Science and Agrobiology, Air 
Quality and Health, Vol. 45, No. 5-6, 1996, pp. 613-630.

[21] L. Lindsay, "Chemical Equilibria in Soil," Wiley, New York, 1979.

[22] X. Li, B. J. Coles, M. H. Ramsey and I. Thornton, "Sequential Extraction of Soil for Multielement Analysis by ICP-AES," Chemical Geology, Vol. 124, No. 1-2, 1995 , pp. 109-123. doi:10.1016/0009-2541(95)00029-L

[23] A. Tessier, P. G. C. Campbell and M. Bisson, "Sequential Extraction Procedure for the Speciation of Particulate Traces Metal," Analytical Chemistry, Vol. 51, No. 7, 1979, pp. 844-851. doi:10.1021/ac50043a017

[24] G. Rauret, R. Rubio and J. F. López-Sanchez, "Optimization of Tessier Procedure for Metal Solid Speciationin River-Sediments," International Journal of Environmental Analytical Chemistry, Vol. 36, No. 2, 1989, pp. 69-83. doi:10.1080/03067318908026859

[25] M. A. Stylianou, D. Kollia, K.-J. Haralambous, V. J. In- glezakis, K. G. Moustakas and M. D. Loizidou, "Effect of Acid Treatment on the Removal of Heavy Metals from Sewage Biosolid," Desalination, Vol. 215, No. 1-3, 2007, pp. 73-81. doi:10.1016/j.desal.2006.11.015

[26] J. Kwapulinski and D. Wiechula, "Forms of Selected Heavy Metals in the Bottom Sediments of Goczalkowice Reservoir, Chemistry and Environmental Protection," Polytechnical University of Lublin, Lublin, Poland, 1993.

[27] R. G. McLaren and L. M. Clucas, " Fractionation of Copper, Nickel, and Zinc in Metal-Spiked Sewage Sludge," Journal of Environmental Quality, Vol. 30, No. 6, 2001, pp. 1968-1975. doi:10.2134/jeq2001.1968

[28] R. Zufiaurrea, A. Olivara, P. Chamorroa, C. Nerín and A. Callizoa, "Speciation of Metals in Sewage Biosolid for Agricultural Uses," Analyst, Vol. 123, No. 2, 1998, pp. 255-259. doi:10.1039/a705168i 